\title{
LETTER
}

\section{Contradictory findings on one-year mortality following ICU delirium}

\author{
Alison E Turnbull ${ }^{1,2^{*}}$, Karin J Neufeld ${ }^{2,3}$ and Dale M Needham ${ }^{1,2,4}$ \\ See related research by Wolters et al. http://ccforum.com/content/18/3/R125
}

In contrast to prior studies (Table 1), Wolters and colleagues [1] reported no significant association between delirium and 1-year survival among Dutch ICU survivors. The authors attributed this finding to a novel adjustment of their Cox survival model for the sum of patients' Sequential Organ Failure Assessment (SOFA) scores (obtained three times daily). Hence, we wish to enquire about the results of their multivariable model if re-run without SOFA adjustment: is the adjusted hazard ratio for delirium statistically significant? This contradictory result also could be attributable to other issues, rather than this unique adjustment that combined SOFA score and length of stay, as described below.

The study's 1 -year mortality was $18 \%$, with $59 \%$ of survivors discharged home. In contrast, 1-year mortality in a prior US study was $41 \%$ [2], raising the question of whether Dutch ICU survivors are healthier than those in some prior studies? Perhaps delirium is more strongly associated with mortality in frail ICU survivors. The Dutch study also reported that delirium was associated with increased cognitive impairment without impaired quality of life. Consequently, we wonder if care for cognitively impaired individuals is better in the Netherlands, hence conferring less risk of mortality to ICU survivors with cognitive impairment.

Finally, what were the results of testing the proportional hazards assumption in the Cox model? If the association between delirium and mortality is time-dependent [3], with the hazard greatest shortly after discharge, as per a prior Dutch study [4], a single hazard ratio over 1 year could attenuate this measure and violate the proportional hazards assumption.

\section{Authors' response}

Annemiek E Wolters and Arjen JC Slooter

We appreciate the opportunity to respond to the thoughtful comments of Dr Turnbull and colleagues.

In our cohort of ICU survivors, we did not find an association between delirium during ICU stay and 1-year mortality. We re-ran the analysis without adjusting for cumulative SOFA scores, and still did not find an association. The difference with other studies must therefore be attributable to other factors, including selection of the population [1]. It should be noted that most studies included ICU patients but were not restricted to survivors of ICU stay, as ours was.

Other explanations for the difference in findings between our study and others could be that the association between delirium and mortality may only be present in frailer former ICU patients, and that aftercare differed between our study and previous investigations. In addition, earlier studies with higher mortality rates included, on average, older patients $[2,5]$. Furthermore, our study included ICU survivors from 2009 to 2011 [1]. The studies with higher mortality rates were conducted at least 5 years earlier, and these participants could not have benefited from similar improvements of care over time [2,5].

The proportional hazard assumption was not violated. The log-minus-log plot showed nearly parallel lines. Also, the interaction term between a function of survival time and delirium was not significant $(P=0.33)$, meaning that the effect of delirium on mortality did not vary significantly with time.

\footnotetext{
* Correspondence: turnbull@jhmi.edu

'Division of Pulmonary and Critical Care Medicine, Johns Hopkins University School of Medicine, 1830 E. Monument St - 5th Floor, Baltimore, MD 21205, USA

${ }^{2}$ Outcomes After Critical IIIness and Surgery (OACIS) Group, Johns Hopkins University, 1830 E. Monument St - 5th Floor, Baltimore, MD 21205, USA Full list of author information is available at the end of the article
} 
Table 1 Selected studies evaluating mortality after ICU delirium

\begin{tabular}{|c|c|c|c|c|c|c|c|}
\hline & \multicolumn{6}{|c|}{ Significant association between delirium and mortality } & \multirow{3}{*}{$\begin{array}{l}\text { No association } \\
\text { Wolters: } \\
\text { Crit Care }\end{array}$} \\
\hline & Ely: & Kiely: & Pisani: & Van Rompaey: & Shehabi: & Abelha: & \\
\hline & $J A M A$ & JAGS & AJRCCM & J Clin Nutr & Crit Care Med & Crit Care & \\
\hline Year & 2004 & 2009 & 2009 & 2009 & 2010 & 2013 & 2014 \\
\hline Location & USA & USA & USA & Netherlands & 5 countries & Portugal & Netherlands \\
\hline Study population & $\begin{array}{l}224 \text { ventilated MICU } \\
\text { and CCU patients }\end{array}$ & $\begin{array}{l}412 \text { ICU survivors with } \\
\text { delirium at discharge }\end{array}$ & 304 MICU patients & $\begin{array}{l}105 \text { non-intubated } \\
\text { ICU patients }\end{array}$ & $\begin{array}{l}354 \text { ventilated } \\
\text { ICU patients }\end{array}$ & $\begin{array}{l}562 \text { SICU patients with } \\
\text { non-emergency surgery }\end{array}$ & $\begin{array}{l}1,101 \mathrm{ICU} \\
\text { patients }\end{array}$ \\
\hline \multicolumn{8}{|c|}{ Patient characteristics at admission } \\
\hline \multirow[t]{3}{*}{ Age (mean (sd)) } & Del $=56(17)$ & $84(7)$ & $75(9)$ & 62 & $62(15)$ & Median (IQR) & $60(17)$ \\
\hline & No del = $54(17)$ & & & & & Del = 65 (54-74) & \\
\hline & & & & & & No del $=64(53-73)$ & \\
\hline \multirow[t]{4}{*}{ Severity of illness (mean (sd)) } & APACHE ॥ & NR & APACHE II minus & APACHE ॥ & APACHE ॥ & Median (IQR) & APACHE IV \\
\hline & Del = 26(8) & & CNS component & Del = 26(8) & $19(7)$ & APACHE ॥ & $61(29)$ \\
\hline & No del = 23(10) & & $22(6)$ & No del = 23(10) & & Del $=9(7-12)$ & \\
\hline & & & & & & No del $=8(5-10)$ & \\
\hline ICU mortality & $13 \%$ & NR & $16 \%$ & $7 \%$ & NR & $1 \%$ & $13 \%$ \\
\hline \multirow[t]{2}{*}{ ICU LOS (median (IQR)) } & NR & $N R$ & 5 & Del $=13.4$ & Del = $16(7-23)$ & Del $=<1(<1-3)$ & Del $=8(5-15)$ \\
\hline & & & & No del $=2.5$ & No del $=4(3-6)$ & No del $=<1(<1-<1)$ & No del $=3(2-5)$ \\
\hline Delirium measure & Binary; time-dependent & Persistence; time-varying & Days; time-varying & Binary & $0,1,2, \geq 3$ days & Binary & Binary \\
\hline \multicolumn{8}{|l|}{ Mortality assessment } \\
\hline Time (months) & 6 & 12 & 12 & 3 and 6 & 1 & 6 & 12 \\
\hline \multirow[t]{2}{*}{ Mortality in ICU survivors } & NR & $39 \%$ & $41 \%$ & $11 \%$ (3 mo) & NR & $13 \%$ & $18 \%$ \\
\hline & & & & $12 \%$ (6 mo) & & & \\
\hline Model & Cox survival & Discrete time survival & Cox survival & Logistic & Cox survival & Logistic & Cox survival \\
\hline \multirow[t]{5}{*}{ Results (95\% Cl) } & $\mathrm{HR}=3.2$ & $\mathrm{HR}=2.9$ & $\mathrm{HR}=1.1$ & OR 3 and 6 mo: & HR $1,2, \geq 3$ versus & $\mathrm{OR}=2.6$ & $H R=1.26$ \\
\hline & $(1.4-7.7)$ & $(1.9-4.4)$ & $(1.02-1.18)$ & $4.3(1.3-14.7)$ & 0 days: & $(1.4-4.8)$ & $(0.93-1.71)$ \\
\hline & & & & $3.8(1.1-13.1)$ & $1.7(1.3-2.3)$ & & \\
\hline & & & & & $2.7(1.6-4.6)$ & & \\
\hline & & & & & $3.7(1.9-7.2)$ & & \\
\hline
\end{tabular}

APACHE, Acute Physiology and Chronic Health Evaluation; CCU, coronary ICU; Cl, confidence interval; CNS, central nervous system; Del, delirium; HR, hazard ratio; HRQoL, health-related quality of life; IQR, interquartile range; LOS, length of stay; MICU, medical intensive care unit; mo, months; NR, not reported; OR, odds ratio; sd, standard deviation; SICU, surgical ICU. 


\section{Abbreviation}

SOFA: Sequential organ failure assessment.

\section{Competing interests}

The authors declare that they have no competing interests.

\section{Authors' contributions}

AET was responsible for the letter's conception and design and drafted the letter. KJN and DMN interpreted the data and critically revised the letter for intellectual content. AEW wrote the authors' response, in tight collaboration with AJCS. All authors read and approved the final letter.

\section{Author details}

'Division of Pulmonary and Critical Care Medicine, Johns Hopkins University School of Medicine, 1830 E. Monument St - 5th Floor, Baltimore, MD 21205, USA. ${ }^{2}$ Outcomes After Critical Illness and Surgery (OACIS) Group, Johns Hopkins University, 1830 E. Monument St - 5th Floor, Baltimore, MD 21205, USA. ${ }^{3}$ Department of Psychiatry and Behavioral Sciences, Johns Hopkins University School of Medicine, 600 North Wolfe Street, Phipps 160, Baltimore, MD 21287, USA. ${ }^{4}$ Department of Physical Medicine and Rehabilitation, Johns Hopkins University School of Medicine, 600 North Wolfe Street, Meyer 1-130, Baltimore, MD 21287, USA.

Published online: 30 January 2015

\section{References}

1. Wolters AE, van Dijk D, Pasma W, Cremer OL, Looije MF, de Lange DW, et al. Long-term outcome of delirium during intensive care unit stay in survivors of critical illness: a prospective cohort study. Crit Care. 2014;18:R125.

2. Pisani MA, Kong SYJ, Kasi SV, Murphy TE, Araujo KLB, Van Ness PH. Days of delirium are associated with 1-year mortality in an older intensive care unit population. Am J Resp Crit Care. 2009;180:1092-7.

3. Buchholz A, Sauerbrei W. Comparison of procedures to assess non-linear and time-varying effects in multivariable models for survival data. Biometrical J. 2011;53:308-31

4. Van Rompaey B, Schuurmans MJ, Shortridge-Bagett LM, Truijen S, Elseviers $\mathrm{M}$, Bossaert L. Long term outcomes after delirium in the intensive care unit. J Clin Nurs. 2009:18:3349-57.

5. Kiely DK, Marcantonio ER, Inouye SK, Shaffer ML, Bergmann MA, Yang FM, et al. Persistent delirium predicts greater mortality. J Am Geriatr Soc 2009:57:55-61. 